\title{
Role of an Anaesthesiologist in the Management of an Embolised ASD Closure Device - Journey from Cathlab to OT
}

\author{
Anjali Modak ${ }^{1}$, Shivani Rao ${ }^{2}$, Amol Singam ${ }^{3}$, Mangesh Choudhari ${ }^{4}$ \\ 1, 2, 3,4 Department of Anaesthesiology, AVBRH Hospital, Jawaharlal Nehru Medical College, \\ Sawangi, Wardha, Maharashtra, India.
}

\section{INTRODUCTION}

Percutaneous device closure of Atrial Septal Defect (ASD) is a commonly used technique as an alternative to surgery with advantages of avoidance of sternotomy, short hospital stay, and fewer complications. However, it may lead to life-threatening complications such as device embolization. We here, report such a case of embolization of the ASD occluder device causing right ventricular inflow obstruction and severe cardiopulmonary compromise. The anaesthesiologist plays the role of a team leader in diagnosing and managing such an emergency from cath lab to transfer of the patient till the retrieval of the device and discharge of the patient.

Atrial septal defect is one of the commonest congenital heart diseases (3.78 / 10000). Shunts from ASD are detected in childhood or young adulthood and are well tolerated in infants and young children, but symptoms of mild fatigue, poor growth or dyspnoea on exertion may be present.(1) Thus, early closure should be considered in such infants. If the defect is small, it may not require any intervention. The shunt, tends to increase with age, and repair is required when ASD is diagnosed. ${ }^{1}$ Patients with huge defect closure to be done between 2 - 5 yrs. Total intravenous anaesthesia or MAC (Monitored Anaesthesia Care) is given in maximum interventional cardiology procedures as patient is required to stay still for up to $1 \mathrm{hr} .^{2}$

Percutaneous transcatheter closure of the defect is most frequently done for ASD closure. ${ }^{3,4}$ It avoids the need for surgery, and is related to few complications. ${ }^{3,5}$ However, complications such as cardiac perforation, fistula formation, thrombosis, arrhythmia (2.6\%) device dislodgement (3.5\%) both to the systemic and pulmonary circulation. 6 They may lead to haemodynamic compromise, inflow or outflow obstruction, which calls for immediate retraction. This is a case of right ventricular inflow obstruction due to embolised closure device.

\section{PRESENTATION OF CASE}

A 15-year-old male, a known case of ASD was admitted in AVBRH Hospital, Sawangi, with complaints of chest pain since 2 months and was taken up for percutaneous catheterisation under general anaesthesia, where transoesophageal echocardiography revealed 2 ASD oval defects of size $8 \mathrm{~mm}$ and $11 \mathrm{~mm}$. Two Cocoon septal occluder of diameter $14 \mathrm{~mm}$ and $18 \mathrm{~mm}$ were inserted. Patient tolerated the procedure, was extubated and shifted to Postoperative Anaesthesia Care Unit (PACU). After around 45 min of procedure, in the PACU, patient had sudden hypotension BP 90 / 48, HR 130 / min with drop in SpO2 level to 90 \%. Patient was immediately taken to cath lab and catheter guided retrieval was tried but failed. The plan was to immediately shift the patient to cardiac OT for surgical retrieval. Shifting the patient to the cardiac OT in minimum door to door time was the main objective.
Corresponding Author:

Dr. Shivani Rao,

Department of Anaesthesia, AVBRH

Hospital, Jawaharlal Nehru Medical

College, Sawangi, Wardha, Maharashtra,

India.

E-mail: shivaniaim4v@gmail.com

DOI: 10.14260/jemds/2020/696

How to Cite This Article:

Modak A, Rao S, Singam A, et al. Role of an anaesthesiologist in management of an embolised ASD closure device: journey from cathlab to OT. J Evolution Med Dent Sci 2020;9(42):3175-3177, 10.14260/jemds/2020/696

Submission 19-07-2020,

Peer Review 13-09-2020,

Acceptance 19-09-2020,

Published 19-10-2020.

Copyright (C) 2020 JEMDS. This is an open access article distributed under Creative Commons Attribution License [Attribution 4.0 International (CC BY 4.0)] 
Patient was kept on $\mathrm{O}_{2} @ 8 \mathrm{~L} / \mathrm{min}$ via Hudson mask. Fluid inflow was continued to maintain the preload. Continuous monitoring of Sp02, ECG, heart rate was done with portable monitors. In the operation theatre, $\mathrm{SpO}_{2}$ had dropped to $84 \%$ with BP 80 / $38 \mathrm{~mm} \mathrm{Hg}$ and HR 150 / min. His cardiopulmonary compromise was temporarily managed with hand ventilation and changing his position on the operating table. Immediate, endotracheal intubation was done. Pulseless electrical activity during expiration prior to induction. Induction was done in head low position. Low tidal volume 5 $\mathrm{mL} / \mathrm{Kg}$ and respiratory rate was kept to 25 to keep low airway pressure. PEEP (Positive End Expiratory Pressure) was avoided. Central venous cannulation was done under echo guidance to prevent entanglement of guide wire in device. Cardiopulmonary bypass (CPB) was established, the right atrial chamber was opened, and device was retrieved followed by Dacron patch closure of ASD. The patient was weaned from $\mathrm{CPB}$ with infusion of nitroglycerin $1 \mu \mathrm{g} / \mathrm{Kg} / \mathrm{m}$ and TEE (Trans Oesophageal Echo) confirmed successful closure of ASD. Patient was haemodynamically stable, shifted to ICU, extubated after 6 hrs and discharged on postoperative day 7 .

\section{DISCUSSION}

ASD accounts for approximately $10 \%$ of congenital cardiac defects and $22-40 \%$ of congenital heart diseases in adults. The major types of ASD are:

1. Ostium secundum ASD (60 - $70 \%)$,

2. Ostium primum ASD (15 - $20 \%)$,

3. Sinus venosus ASD (5 - $15 \%)$,

4. Unroofed coronary sinus.

An ostium secundum ASD is suitable for percutaneous closure. Presentation depends upon the magnitude of the left to right shunt. Clinical examination may reveal fixed splitting of the second heart sound coupled with a pulmonary flow murmur. ${ }^{2}$ The electrocardiogram of an ASD is Right Bundle Branch Block (RBBB) and axis deviation (right for secundum and left for primum).

Closure of an ostium secundum inhibits development of pulmonary hypertension.

Percutaneous device closure is nowadays the commonly done procedure. A balanced anaesthetic technique with shortacting drugs is indicated. Muscle relaxation and endotracheal intubation is required and maintenance of anaesthesia on an inhalation technique or total IV anaesthesia (propofol + remifentanil). Nitrous oxide should be avoided because of the potential to increase intravascular bubble size. Analgesics (e.g. acetaminophen) and anti-emetics may be administered intraoperatively. The patient should be monitored in an appropriate recovery area before discharge to the ward. ${ }^{2}$ In our case, balanced anaesthesia with endotracheal intubation and muscle relaxation with maintenance of propofol and fentanyl was chosen. Complications as, cerebral embolism, cardiac tamponade, arrhythmia and device embolization can occur. ${ }^{7}$ These complications require immediate surgical intervention. The closure of ASD by a percutaneous intervention may fail for several reasons, example large defect, extremely mobile interatrial septum, septum rupture. ${ }^{8}$
When ASD devices embolised, usually there is no significant haemodynamic instability but if embolised ASD device reaches to RVOT / PA or left side of the heart, it may lead to severe haemodynamic compromise and turn out be even fatal. ${ }^{9}$ However, as an anaesthesiologist, we should be ready to deal with complications as in this case. Transcatheter retrieval should be attempted, but on the other hand multiple retrieval attempts prolongs procedure time, hypothermia, bleeding and anaemia. Pala et al. reported the case of interatrial septal closure device embolised into aortic arch, which was successfully retrieved percutaneously. ${ }^{10}$ However, in our case transcatheter retrieval failed and plan was to immediately shift the patient to OR (Operating Room) for surgical retrieval of the device.

Early detection and immediate intervention are the key for better prognosis and survival. Also, the major burden lies on the transferring team, thus it should be well coordinated and lead by the anaesthesiologist as a team leader. The anaesthesiologist should be well equipped and be ready for any immediate intervention required even during the transfer. In our case, during the transfer, three step management was done. Firstly, the cardiac OT surgeon and anaesthetist was informed about the situation and arrival of the patient. Secondly, as patient was landing up in cardiopulmonary compromise, we as an anaesthesiologist had to monitor, manage and guide through the process, thus portable ECG, pulse oximeter and hear rate was taken along with. Thirdly, it was very important to explain the patient about the situation and calming him.

In the OR, immediate endotracheal intubation should be preferred to maintain the hemodynamic as the device may migrate to RVOT / PA or left side of the heart. As in this case, patient was becoming severely haemodynamically compromised, due to embolisation of the device leading to right ventricular inflow obstruction so hand ventilation was done to temporarily manage the cardiopulmonary compromise followed by endotracheal intubation. Head low position for induction was chosen to prevent right ventricular inflow obstruction. The anaesthesiologist may also perform TEE to guide surgeon for location of device and its complete retrieval. The successful closure of ASD could be confirmed by postoperative TEE.

\section{CONCLUSIONS}

Embolisation of the device may produce immediate haemodynamic and respiratory complications. Therefore, anaesthesiologist should be vigilant enough and be prepared for such emergency situations. Timing is of utmost importance in these cases; thus, a minimum transfer time should be the goal. Moreover, transferring the patient from cath lab to OT, managing the patient intraoperatively, stabilizing the patient and coordinating as a team leader, makes the anaesthetist the centre of management in these cases.

Financial or other competing interests: None.

Disclosure forms provided by the authors are available with the full text of this article at jemds.com. 


\section{REFERENCES}

[1] American Heart Association. Guidelines for the evaluation and management of common congenital cardiac problems in infants, children and adolescents. www.americanheart.org/presenter.jhtml?identifier $=121$ 0.

[2] Calvert PA, Klein AA. Anaesthesia for percutaneous closure of atrial septal defects. Continuing Education in Anaesthesia Critical Care \& Pain 2008;8(1):16-20.

[3] Das S, Kumar P, Bhardwaj V, et al. Anesthetic management of Amplatzer atrial septal defect closure device embolization to right ventricular outflow tract. Saudi J Anaesth 2016;10(3):335-8.

[4] Jo SS, Han SJ, Jung MJ, et al. Transcatheter closure of atrial septal defect using Amplatzer septal occluder. Korean Circ J 2002;32:17-24.

[5] Chessa M, Carminati M, Butera G, et al. Early and late complications associated with transcatheter occlusion of secundum atrial septal defect. J Am Coll Cardiol 2002;39(6):1061-5.

[6] Hamur H, Onk OA, Degirmenci H, et al. The retrieval of atrial septal defect closure device embolized into aortic arch. Intractable Rare Dis Res 2016;5(2):114-6.

[7] Majunke N, Bialkowski J, Wilson N, et al. Closure of atrial septal defect with the Amplatzer septal occlude in adults. Am J Cardiol 2009;103(4):550-4.

[8] Chiappini B, Gregorini R, Di Eusanio M, et al. Embolization of an Amplatzer atrial septal closure device to the pulmonary artery. J Card Surg 2008;23(2):164-7.

[9] Ko SF, Liang CD, Yip HK, et al. Amplatzer septal occluder closure of atrial septal defect: evaluation of transthoracic echocardiography, cardiac CT, and transesophageal echocardiography. AJR Am J Roentgenol 2009;193(6):1522-9.

[10] Pala S, Açar G, Tigen K, et al. Percutaneous retrieval of an interatrial septal occluder device embolized into the aortic arch. Turk Kardiyol Dern Ars 2010;38(7):502-4. 